\title{
Renewable Biomethane From Land and Ocean Energy Crops and Organic Wastes
}

\author{
David P. Chynoweth ${ }^{1}$ \\ Department of Agricultural and Biological Engineering, P.O. Box 110570, University of Florida, Gainesville, \\ FL 32611-0570
}

\begin{abstract}
Additional index words. anaerobic digestion, biomass, compost, energy, methane, space mission, wastes
Summary. Production of methane via anaerobic digestion of energy crops and organic wastes would benefit society by providing a clean fuel from renewable feedstocks. This could replace fossil fuel-derived energy and reduce its environmental impacts, including global warming and acid rain. Although biomass energy is more costly than fossil fuel-derived energy, trends to limit carbon dioxide and other emissions through regulations, carbon taxes, and subsidies of biomass energy would make it cost competitive. Methane derived from anaerobic digestion is competitive in efficiencies and costs with other biomass energy forms including heat, synthesis gases, and ethanol. The objective of this paper is to review the results and conclusions of research on biomass energy conducted under the sponsorship of the gas industry with periodic co-funding from other agencies. The scope of this program was to determine the technical and economic feasibility of production of substitute natural gas (SNG) from marine and terrestrial biomass and organic wastes using anaerobic digestion as a conversion process. This work began in 1968 and continued until about 1990, ending as a result of low energy prices in the U.S. and reduced emphasis on renewable energy. For each of these feedstock categories, growth or collection (in the case of wastes), harvesting, conversion by anaerobic digestion, and systems and economic analysis were addressed. More recently the potential use of anaerobic digestion for stabilization and recovery of nutrients from solid wastes during space missions was studied with funding from NASA. The application of this process for that function as well as treatment of wastewater and waste gases generated during space missions is addressed.
\end{abstract}

Several research programs investigated energy crops (aquatic and marine plants, grasses, and woods) and municipal solid wastes (MSW) coupled with anaerobic digestion for generation of renewable substitute natural gas. These programs integrated research on crop production and harvesting, collection of municipal solid wastes, conversion of these feedstocks to methane by anaerobic digestion, and systems analysis. The objective of this paper is to summarize the results of these programs as well a more recent project to evaluate use of anaerobic digestion for processing wastes generated during long-term space missions. The details of most of the information are presented in detail in a review by Chynoweth (2002).

\section{Energy Crops}

Research results on anaerobic digestion of energy crops were summarized by Chynoweth et al. (2001) and Chynoweth (2002). Resource potential estimates for U.S. renewable feedstocks (Table 1) have been reported at 7 EJ ( 1 exajoule $\approx 1$ quad $\approx 10^{15} \mathrm{Btu}$ ) for wastes and $22 \mathrm{EJ}$ for terrestrial biomass (grasses and woods). To add perspective to this, all existing cropland (fallow and in production for food and feed) would be required to meet the existing U.S. energy demands (about100 EJ per year). The potential for marine biomass is huge at greater than this requirement. All of the U.S. energy needs could be supplied by marine macroalgae grown on about 260 million ha (1 million mile ${ }^{2}$ ) of ocean (Chynoweth 2002). However, this optimistic estimate has many uncertainties related primarily to design of offshore farms. Table 2 shows that the cost of methane from these renewable energy systems was significantly higher (2 to 10 times) than

\footnotetext{
${ }^{1}$ To whom reprint requests should be addressed; e-maildchyn@ufl.edu.
}

fossil-derived energy and interest in continued Abbreviations

funding of their development dwindled with continuation of energy gluts and depressed prices in the 1980s.

Figure 1 and Table 3 summarize the assumptions and economics for a typical biomass energy plant processing about $1000 \mathrm{t} \cdot \mathrm{d}^{-1}$ (dry) of napiergrass and generating a net energy of $10^{13}$ $\mathrm{J} \cdot \mathrm{d}^{-1}$. The system would require about 7,600 ha of and thirty $8500-\mathrm{m}^{3}$ digesters.

The cost of methane from this system was estimated at $\$ 6.70$ (1990 prices) per GJ, compared to $\$ 2.50$ per GJ (1990 prices) for fossil methane. Costs could be reduced most significantly by increasing feed biodegradability and feed energy content, and use of biogas without removal of carbon dioxide.

Marine biomass offers the highest technical potential for large scale biomass energy farms. The available ocean area and coastline area provide under-used resources for marine farming. Growth rates of marine macroalgae far exceeded by those of terrestrial based plants, mainly because of their lack of water limitation. The major factor limiting natural macroalgal growth is nutrients. Overcoming this limitation, and high cost constitute the major challenges of ocean farming. Studies summarized by Chynoweth (2002) suggest that upwelling is too costly and that the most attractive option is recycle of nutrients from conversion processes. Growth is the major cost component of macroalgal farms and could be reduced by using nearshore versus open ocean farms. The major technical challenge remaining is to successfully grow macroalgae in the open ocean. Numerous attempts to do so have been unsuccessful.

The suitability of biomass and waste feedstocks for anaerobic digestion depends significantly on the biochemical methane potential (BMP). This parameter is determined using a standardized laboratory biogasifica-

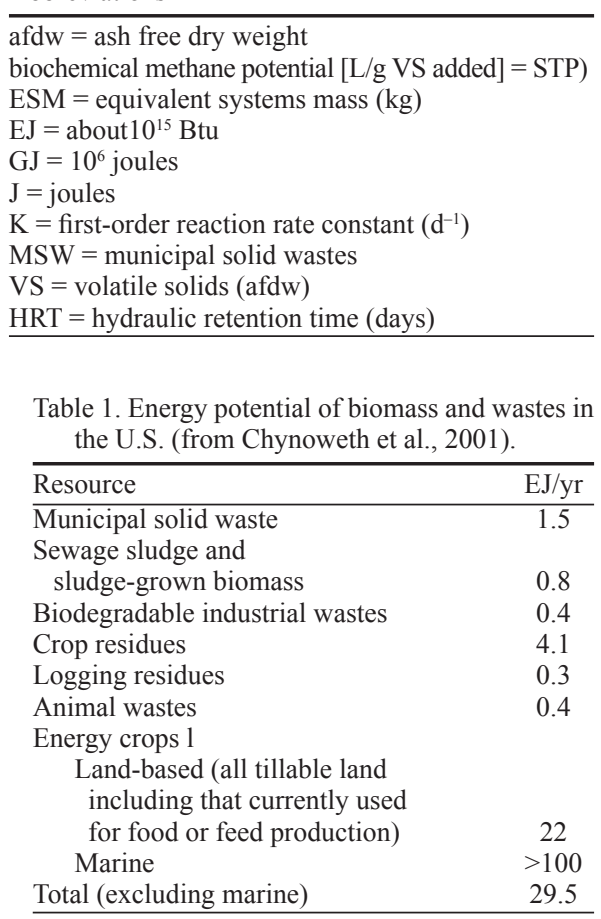

Table 2. Cost estimates for production of biomethane from energy crops. (1990 U.S. Gas costs about $\$ 2.50$ per GJ; from Chynoweth et al., 2001)

\begin{tabular}{lc}
\hline $\begin{array}{l}\text { Energy } \\
\text { crop }\end{array}$ & $\begin{array}{c}\text { Methane cost } \\
\$ / \mathrm{GJ}\end{array}$ \\
\hline Grass (sorghum) & $6-8$ \\
Wood (poplar) & $3-7$ \\
Seaweed (kelp) & $6-14$ \\
\hline
\end{tabular}

tion assay to determine the ultimate methane potential $\left(\mathrm{B}_{\mathrm{o}}, \mathrm{L} / \mathrm{g}\right.$ organic matter added) and conversion rate $\left(\mathrm{k}, \mathrm{d}^{-1}\right)$ for various feedstocks. BMP data for several feedstocks analyzed are shown in Table 4. In general, most macroalgal 
Feedstock

-Napiergrass: 54 dry tons/ha/yr

-Growth Area: 7,600 ha

-Storage: ensiled, in 49 silos

\section{Conversion}

$\cdot 1,000 \mathrm{t} \cdot \mathrm{d}^{-1}$ (dry)

- Thirty $8,500-\mathrm{m}^{3}$ digesters, $55^{\circ} \mathrm{C}$, HRT $35 \mathrm{~d}$

- Organic conversion: $75 \%$

\section{Energy product}

$\cdot 101^{3} \mathrm{~J} \cdot \mathrm{d}^{-1}$

$\cdot 3 \times 10^{15} \mathrm{~J}$ year $^{-1}$

Fig. 1. Base case for production of methane from grasses: assumptions (from Chynoweth et al. 2001).

species examined gave good yields and rates of conversion.

Anaerobic digestion of marine macroalgae has been demonstrated with both high conversion rates and yields (Chynoweth, 2002). These parameters vary among different species and within the same species depending upon growth conditions. Macroalgae have a high salt content and require adaptation of a halophilic inoculum which may be obtained from a conventional digester or halophilic anaerobic environments. The performance of inocula from both sources is similar.

The digester of choice for this feedstock category is one of several that have longer solids than hydraulic retention times. Promising results were obtained with vertical and horizontal solids concentrating reactors designed to retain solids longer than liquids. Good kinetics and conversion were also obtained with fluidized bed and multi-phase digester designs.

The estimated overall costs of producing substitute natural gas from marine macroalgae were higher than those of grass, wood, and waste systems and substantially higher than fossil fuels in the U.S. (Table 2). This is related to the elevated cost of farming in the ocean, which may be reduced substantially by recovery of byproducts and stimulation of mariculture. The economics of waste conversion systems are the best because of tipping fees (waste processing charges) associated with treatment. It should be recognized that the current low price of fossil fuels is dependent upon real subsidies (e.g., tax credits and costs related to protection of foreign oil reserves) and hidden subsidies, such as relaxed environmental regulation.

The major incentive for reconsideration of energy crops for conversion to methane is the environmental impact of fossil fuel use, related to global warming caused in part by release of carbon dioxide into the atmosphere.. The severity of this impact has led to international discussions of imposing a carbon tax in the range of $\$ 50$ to $\$ 100$ per $t$ of carbon released as carbon dioxide which would significantly increase energy prices. Considering this possible tax and the cost of removal of carbon dioxide from combustion gas effluents, biomass would readily become a viable option. It is important to realize that carbon dioxide released from combustion of plants or organic wastes is carbon neutral, i.e., balanced by current photosynthesis. On the contrary, carbon dioxide released from the historic reservoir of fossil fuels exceeds that removed by photosynthesis resulting in increases in atmospheric levels. Furthermore, the inevitable long-term depletion of fossil fuel resources and reduced dependency on foreign imports provide strong additional incentives for rapid development of renewable energy resources.

\section{Organic Wastes}

Research results on anaerobic digestion of organic wastes were summarized by Chynoweth (2002). Because biomethanogenesis decomposes organic matter with production of a useful energy product (methane) and compost, anaerobic digestion of organic wastes is receiving increased attention for that application. With increased levels of waste production, limited area for landfilling or application, and increased awareness of environmental impact, alternative methods for treatment of solid and agricultural wastes are being sought. Currently these wastes release undesired methane into the atmosphere due to anaerobic conversion in landfills, lagoons, or stockpiles. Treatment and recovery of this gas in reactors would reduce this source of atmospheric methane.An attractive option for stabilization of the organic fraction of these wastes is to separately treat this material by composting and applying the stabilized residues on land as a soil amendment. The residues would reduce irrigation requirements and prevent erosion. The compost from treatment of wastes from a population of 100,000 could be applied on a sustained basis on less than 2,000 ha of land. This scheme, however, requires effective separation of undesired components such as metals, glass, plastics, and toxic compounds which affect the quality of residues more than the conversion process. In European countries, who lead in this field, the most effective method of separation has been determined to be source separation, resulting in compost with sufficiently low

\begin{tabular}{lcc} 
Table 3. Base case for production of methane from grasses: economics (from Chynoweth et al., 2001)) \\
\hline Operation & $\$ / G J$ & Percent of total cost \\
\hline Crop production & 1.74 & 26.1 \\
Harvest and storage & 1.29 & 19.4 \\
Transportation & 0.48 & 7.3 \\
Conversion & 2.10 & 31.5 \\
Residue recycle & 0.11 & 1.6 \\
Gas cleanup & 0.94 & 14.1 \\
Total & 6.66 & 100
\end{tabular}

Table 4. Range of biochemical methane potential data for biomass or waste feedstocks of which several samples were analyzed $(\mathrm{Bo}=$ biochemical methane potential; $\mathrm{VS}=$ ashfree dry weight; $\mathrm{k}=$ conversion rate constant; from Chynoweth, 2002)

\begin{tabular}{lcc}
\hline Sample & B (STP) & $\mathrm{k}$ \\
$\left(\mathrm{d}^{-1}\right)$
\end{tabular}

levels of contaminants for land disposal. Although aerobic composting continues to be a more popular process for stabilization of these wastes, anaerobic digestion has the advantages of methane production and lack of need for aeration or mixing. Furthermore, fewer odors are experienced with anaerobic composting since the odorous compounds associated with aerobic composting are converted to methane. Several full-scale anaerobic composting plants are in operation in Europe and Asia.

\section{Space Mission Wastes}

Research results anaerobic digestion of space milssion wastes were summarized by Chynoweth et al. (2003). During long-term space missions, e.g., a 600-d mission to Mars, a crew of six may produce about 7 to $8 \mathrm{~kg}$ (afdw) of solid wastes per day. The major fraction (about $52 \%$ ) is estimated to consist of food wastes and residues from salad and other crops grown for oxygen regeneration and food. The technical feasibility of applying anaerobic digestion for reduction and stabilization of the organic fraction of solid wastes generated during space missions was investigated. This process has the advantages of not requiring oxygen or high temperature or pressure while producing methane, carbon dioxide, nutrients, and compost as valuable products. High-solids leachbed anaerobic digestion selected for this application (Fig. 2) involved a solid-phase fermentation with leachate recycle between new and old reactors for inoculation, wetting, and removal of volatile organic acids during startup. After anaerobic conversion is complete, the compost bed may be used for air biofiltration and plant growth medium (following pasteurization). The nutrient-rich leachate may also be used as a vehicle for nutrient recycle.

Anaerobic BMP assays were run on several waste feedstocks expected during space missions, including primary crop residues (from 


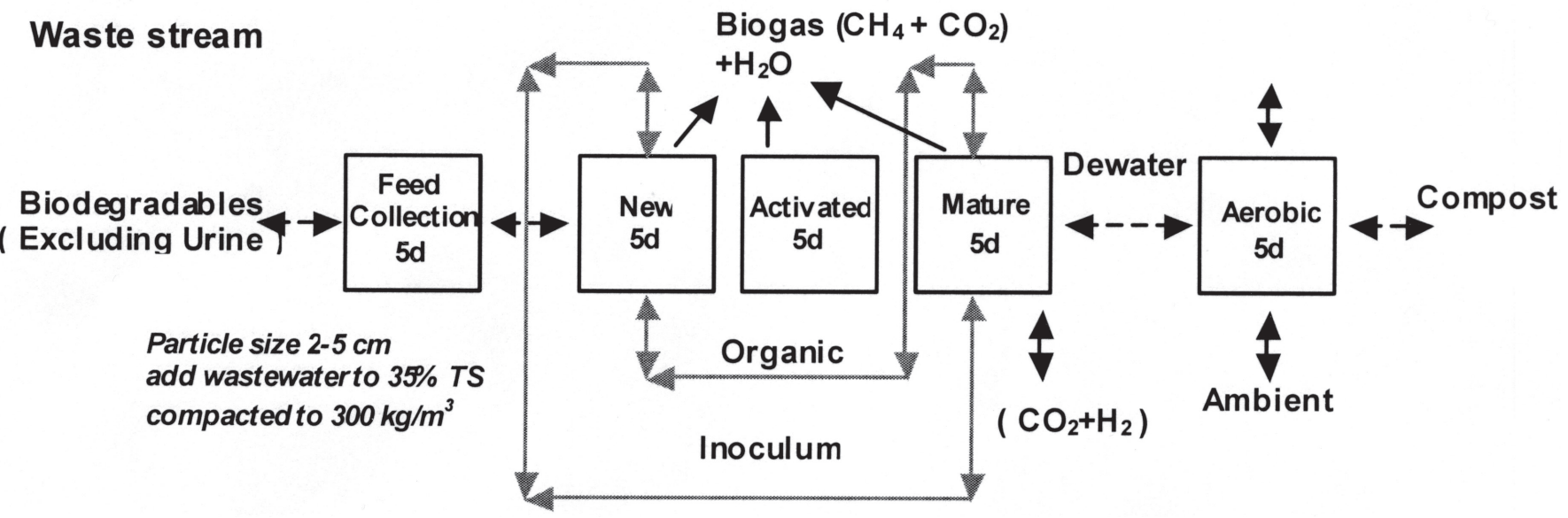

Fig. 2. Sequential batch anaerobic composting system for space missions (from Chynoweth et al., 2003).

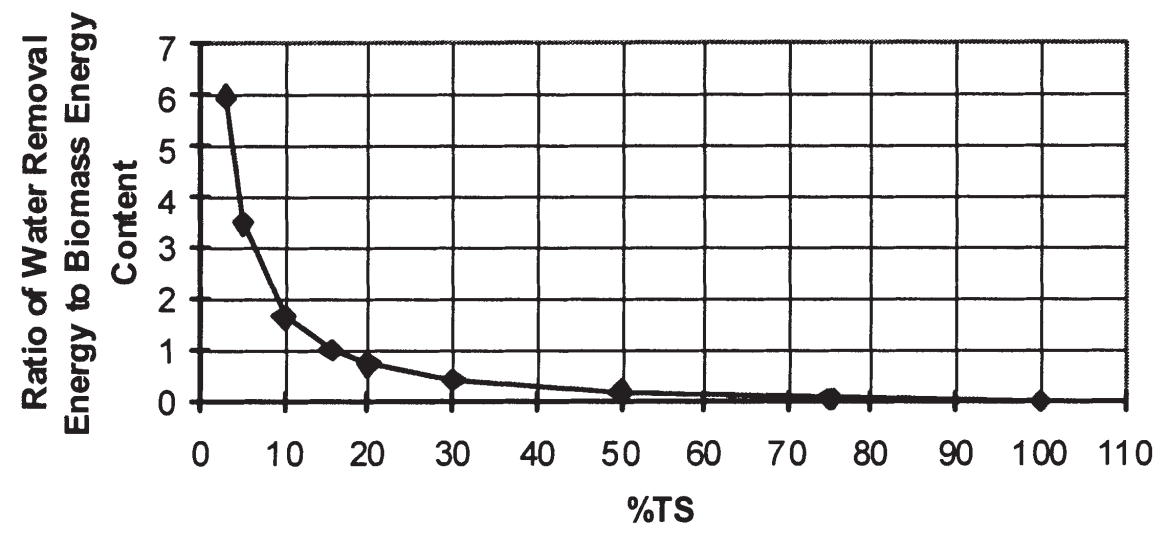

Fig. 3. Influence of feed solids content on energy requirement to remove water for thermal conversion processes (from Chynoweth et al 2001).

wheat, tomato, peanut, sweet potato, potato, and rice processing), salad crops (cabbage, carrot, lettuce, onion, radish, and red chard), and different paper and packaging materials. Extent and rates of conversion of these feedstocks and various paper types were determined. The methane yields ranged from 0.14 to $0.36 \mathrm{~L} / \mathrm{g}$ VS added. The highest yields and rates were observed for peanut and rice residues and various paper types.

Modifications for operation of a leachbed anaerobic digestion process in space environments were incorporated into a new design, including flooded operation to force leachate through densified feedstock beds and separation of biogas from leachate in a gas collection reservoir. This mode of operation at a laboratory scale with a typical space solid waste blend resulted in stable performance, $85 \%$ conversion, and a methane yield of $0.3 \mathrm{~L} / \mathrm{g} \mathrm{VS}$ (VS = volatile solids $=$ ash-free dry weight, a measure of organic matter) added after a retention time of $15 \mathrm{~d}\left(\mathrm{~T}=35^{\circ} \mathrm{C}\right.$, atmospheric pressure).

A detailed analysis of this process was conducted to design a prototype system sized for a space mission with a six-person crew. The mass, energy, and water balances of the process and equivalent system mass (ESM) analyses were determined. ESM is a parameter (expressed as kg) used by space scientists and engineers to compare technologies for space applications and includes volume, weight, power requirements, and crew time. In order to process the $7.5 \mathrm{~kg}$ (afdw) of organic matter produced daily by a crew of six, a five-digester system with a total volume of $2 \mathrm{~m}^{3}$ and mass of $181 \mathrm{~kg}$ would be required. The ESM of anaerobic digestion compared favorably with other technologies for solid waste stabilization. The possible use of high-solids anaerobic digestion for other space functions has been pointed out, including reformation of hydrogen and carbon dioxide produced from electrolytic oxygen production from water and respiration, respectively, and coarse treatment of cabin wastewater and air.

A full-scale prototype space digester has been constructed and placed into operation. The system design is based on a University of Florida patented process for odorless bioconversion of organic solid wastes to methane and compost by anaerobic digestion. It is intended to be the principal component in a bio-regenerative solid waste management (SWM) system for advanced life support on long-term space missions. The system consists of five reactors and two gas-liquid separators designed for operation under conditions of microgravity. During any week of operation, one reactor is being used for feed collection and compaction, three for stage-wise anaerobic composting, and one for post-treatment aerobic stabilization while simultaneously serving as a bio-filter in the pretreatment of cabin air within the air revitalization subsystem. Each reactor carries its 1-week charge of feedstock through all five stages of bioconversion in completing a 5-week batch cycle. In a typical run of this system, the methane yield was $0.31 \mathrm{~L} / \mathrm{g}$ VS (calculated from VS reduction) added and the VS reduction was $85 \%$ after a retention time of $15 \mathrm{~d}$.

\section{Comparison of Anaerobic Digestion to Other Conversion Processes}

(Chynoweth et al., 2001). Biomass may be converted to a variety of energy forms including heat (via burning), steam, electricity, hydrogen, ethanol, methanol, and methane. Selection of a product for conversion is dependent upon a number of factors, including need for direct heat or steam, conversion efficiencies, energy transport, conversion and use hardware, economies of scale, and environmental impact of conversion process waste streams and product use. Under most circumstances methane is an ideal fuel. Currently it represents about 20\% of the U.S. energy supply. Related to this, an extensive pipeline distribution system and a variety of hardware are in place for its domestic, municipal, and industrial use. Compared to other fuels, methane use produces less atmospheric pollutants and carbon dioxide per unit energy. Because methane is a comparatively clean fuel, the trend is toward its increased use for appliances, vehicles, industrial applications, and power generation. Although some applications require high purity methane, it can be used in a variety of states of purity, and efficiencies of transport and energy conversion are good compared to electricity. Other fuels such as methanol and hydrogen are not well developed commercially for production and use and are more difficult to produce from biomass. Ethanol is becoming a popular biomass-derived fuel. Although it has the advantage of easy storage and transport, the fermentation process for its production requires extensive feedstock pretreatment and pure culture maintenance, and energy requirements associated with feed pro- 
cessing and product separation result in overall low process efficiencies. These problems are not characteristic of processes for biological conversion of biomass to methane.

Methane may be produced from biomass by either thermal gasification or biological gasification (commonly referred to as anaerobic digestion). Economic application of thermal processes is limited to feeds with either a low water content $(<50 \%)$ or those having the potential to be mechanically dewatered inexpensively. This limitation is linked to energy needed for evaporation of water in order to achieve high temperatures required for the process (Fig. 3). Note that feedstocks containing $15 \%$ total solids require all of the feed energy for water removal. Also thermal processes for methane production are only economic at large scales and generate a mixture of gaseous products (e.g., hydrogen and carbon monoxide) that must be upgraded to methane. This paper has emphasized biological gasification which is a low-temperature process that can convert wet or dry (with added water) feeds economically at a variety of scales. The product gas is composed primarily of methane and carbon dioxide with traces of hydrogen sulfide and water vapor. The major limitation of biological gasification is that conversion is usually incomplete, often leaving as much as $50 \%$ of the organic matter unconverted. However, land application of these compost residues is compatible with topsoil maintenance and related sustainable use of the land for growth of biomass. Process rates are significantly lower than those of thermal processes and the bacteria involved require a balanced diet of nutrients that may not be available in some feedstocks.

\section{Conclusion}

As the population increases and technology development begins to result in significant resource depletion and environmental deterioration, humans must take a global view of life based on the ground rules for sustaining our species in a manner that is compatible with preservation of the biosphere and it's resources. This will require production of food, feed, and energy by technologies that are indefinitely sustainable and which have minimal environmental impacts. Amajor shift is needed toward renewable resources for energy and sustainable agricultural practices for production of food and feed. Emphasis must be placed on recycling of all nonrenewable resources, e.g., minerals, metals, etc., and elimination of discharge of anthropogenic materials and compounds into the environment, e.g., plastics and toxic chemicals. Derivation of methane from energy crops could play a major role toward these objectives for achieving sustainability.

\section{Literature Cited}

Chynoweth, D.P. Review of biomethane from marine biomass. 2002. A report prepared for Tokyo Gas Company. http://www.agen.ufl. edu/aboutchyn/download/Publications_DC/ Reports/marinefinal_FT.pdf.

Chynoweth, D.P., Haley, P., Owens, J., Teixeira, A., Townsend, T., Xu, Q., and Choi, H. 2003. Anaerobic composting for recovery of nutrients, compost, and energy from solid wastes during space missions. Paper presented at the ORBIT Conference, Perth, Australia. http://www.agen. ufl.edu/aboutchyn/download/Publications_DC/ Non-Refereed/2003_sebacspaceORBIT.pdff.

Chynoweth, D.P., J.M. Öwens, and R.L. Legrand. 2001. Renewable methane from anaerobic digestion of biomass. Renewable Energy 22:1-8. 